Anales de Literatura Hispanoamericana

ISSN-e: 1988-2351

\title{
Prólogo: en busca de la canción perdida
}

Marcela Crespo Buiturón ${ }^{1}$

[en] Prologue: in search of the lost song

Sumario. 1. Desde el exilio pandémico. 2. Una singularidad constitutiva. 3. Una canción perdida... 4. ... en Buenos Aires al Sur.

Cómo citar: Crespo Buiturón, M. (2021) Prólogo: en busca de la canción perdida, en Anales de Literatura Hispanoamericana 50, 15-20.

\section{Desde el exilio pandémico}

En estos tiempos de pandemia, me resulta especialmente perturbador hablar del exilio republicano español, porque empiezo a imaginar -tal vez insensatamente- formas especulares... No sé si en todo el mundo, pero desde mi pequeño rincón del Sur, también percibo una sociedad feroz y políticamente dividida: la que defiende el aislamiento físico (es inquietante que haya sido anunciado como aislamiento social) y la anticuarentena. Amistades y familias escindidas, apoyando una u otra postura. Entre aquellas dos Españas y estas dos Argentinas, con sus posicionamientos políticos inconciliables y luchas sin cuartel: el dolor y la agonía de sus habitantes, encerrados en sus casas, atemorizados... ¿Qué memoria quedará de esta nueva modalidad de guerra civil? ¿Qué narrará la Historia de estos pueblos castigados por polarizaciones destructivas?

El año 2019, entre el 15 y el 18 de octubre, hemos tenido la oportunidad de reunirnos en Buenos Aires, en el marco de las VI Jornadas de Literatura Argentina, que se convocaron bajo el lema Argentina Transatlántica, coorganizadas entre la Universidad del Salvador (USAL) y el Transatlantic Project, de la Brown University, dirigido por Julio Ortega. Investigadores, docentes y alumnos nos hicimos eco del Homenaje Plural $80^{\circ}$ años después, organizado por el Grupo Gexel de España, en ocasión del aniversario del exilio republicano español. Con la coordinación general de Manuel Aznar Soler, catedrático de la Universidad Autónoma de Barcelona, se ha llevado a cabo en diferentes países, un gran número de eventos solidarios con esta propuesta, con el aval de la Comisión Interministerial del Gobierno de España, creada a tal efecto.

Como resultado de este encuentro en Buenos Aires, se han editado: un número monográfico de la revista Gramma, de la Escuela de Letras de la Universidad del Salvador, en el que se compilaron trabajos sobre exiliados republicanos españoles en Argentina y este dossier acerca de la segunda generación del exilio, la de los hijos, haciendo especial énfasis en la obra de una de ellos, María Rosa Lojo.

\section{Una singularidad constitutiva}

Dentro del panorama literario argentino, Lojo (www.mariarosalojo.com.ar) se presenta como una autora singular por varios motivos. Ante todo, ha desarrollado una intensa carrera dual tanto en el área de la investigación como de la ficción. 
En este último campo es autora de obras como: Visiones (1984), Marginales (1986), Canción perdida en Buenos Aires al Oeste (1987), Forma oculta del mundo (1991), La pasión de los nómades (1994), La princesa federal (1998), Esperan la mañana verde (1998), Una mujer de fin de siglo (1999), Historias ocultas en la Recoleta (2000), Amores insólitos de nuestra historia (2001), Las libres del Sur (2004), Finisterre (2005), Cuerpos resplandecientes. Santos populares argentinos (2007), Árbol de familia (2010), Bosque de ojos (2011), El libro de las Siniguales y del único Sinigual (2016) ${ }^{2}$, Todos éramos hijos (2014) y Solo queda saltar (2018). Varias de estas obras han sido traducidas, e incluso premiadas, en países tan lejanos de la Argentina como Canadá o Tailandia.

En el área de la investigación publicó los libros La 'barbarie' en la narrativa argentina (siglo XIX), Sábato: en busca del original perdido, El símbolo: poéticas, teorías, metatextos, Cuentistas argentinos de fin de siglo como única autora y Los 'gallegos' en el imaginario argentino. Literatura, sainete, prensa, Identidad y narración en carne viva y Leopoldo Marechal y el canon del siglo XXI, en tanto editora/ directora de investigación y coautora. Dirigió tres ediciones críticas: Lucía Miranda (1860), de Eduarda Mansilla; Sobre héroes y tumbas, de Ernesto Sábato (Colección Archivos), y Diario de viaje a Oriente (1850-51), de Lucio V. Mansilla. Acredita más de ciento noventa publicaciones de investigación, entre artículos en revistas especializadas, capítulos de libros y actas de congresos.

Esa condición bifronte le valió distinciones puntuales y reconocimientos a la trayectoria, que culminaron en los últimos años con la Medalla de la Hispanidad (2009), la Medalla del Bicentenario de la Ciudad de Buenos Aires (2010), el Premio a la Trayectoria en Literatura de Artistas Premiados Argentinos (2014) y el Gran Premio de Honor de la Sociedad Argentina de Escritores (2018). Acaba de ser designada por el Comité Internacional de la Medalla Europea de Poesía y Arte Homero, para recibir este galardón en $2021^{3}$.

Asimismo, es Miembro Correspondiente de la Academia Norteamericana de la Lengua Española (2015), Miembro del Consejo de Administración de la Fundación Sur (2017), instituida por Victoria Ocampo, y fue electa Académica de Honra de la Real Academia Gallega en 2019.

No es casual que sus libros reflejen sus facetas de ensayista, scholar y creadora múltiple, con una escritura compleja y de clasificación problemática: "En sus textos, se entrelazan géneros sin dificultades: su narración se vuelve poética, su lírica en prosa se distingue difícilmente de sus microficciones, sus novelas adquieren modalidades de ensayo y sus textos metaficcionales pocas veces se alejan de sus ficciones..." (Crespo Buiturón, 2018: 2)

Pero no solo en este, sino en otros aspectos, María Rosa Lojo puede ser caracterizada como una escritora "del borde": un espacio incómodo pero fecundo, donde no solo se cruzan los géneros y los discursos, sino las pertenencias, las patrias, los imaginarios. Ese intersticio constitutivo proporciona a la autora una perspectiva singular y única, desde la que se discuten y se ponen en cuestión todas las dicotomías reductivas.

\section{Una canción perdida...}

Una canción viene sonando desde lo más profundo, desde lo más lejano: es la música de las hojas de aquellos árboles añejos del viejo mundo, frotándose al viento, la que María Rosa, Irene, Rosaura, Rosalind, Carmen, Frik y Rosa ${ }^{4}$ escuchan... la que, tal vez, Victoria, Eduarda ${ }^{5}$ y $\operatorname{tantas}$ otras mujeres de nuestra historia han escuchado... Esa canción siempre ha estado sutilmente presente en los textos de esta exiliada hija. Algunas veces, suena más fuerte... otras, parece enmudecer, pero sigue ahí, enlazada a cada palabra, a cada silencio.

María Rosa Lojo es hija de un exiliado republicano gallego y de una inmigrante madrileña, que se encontraron en este peculiar entre-lugar que ha sido para ellos, Buenos Aires: una urbe en la que confluyen, paradójicamente, la tierra receptora -accidental y provisoria- y la idealizada patria perdida del exilio... Este encuentro ha ido construyendo un escenario (devenido muchas veces casi en personaje), por momentos confuso, fragmentado y conflictivo, aunque con espacios diáfanos, cada vez más frecuentes en la medida en

\footnotetext{
${ }^{2}$ Cabe señalar que esta obra fue publicada primero en lengua gallega, como O Libro das Seniguais e do único Senigual (Galaxia: Vigo, 2010).

3 "María Rosa Lojo recibirá la Medalla Europea de Poesía y Arte.” Agencia Télam. Buenos Aires. 4 de julio de 2020. https://www.telam.com.ar/notas/202007/485430-maria-rosa-lojo-medalla-europea-de-poesia-y-arte.html

${ }^{4}$ Personajes de las novelas de Lojo, a los que varios críticos han considerado alter ego de la autora.

${ }^{5}$ Victoria Ocampo y Eduarda Mansilla, personajes históricos en los que Lojo se ha inspirado para escribir Las libres del Sur y Una mujer de fin de siglo, respectivamente.
} 
que la obra de la exiliada hija ha ido madurando y hallando su lugar en esa tierra que le ha permitido, sin dejar de ser la hija de los barcos, al menos plantar las raíces que venían flotando en el viento.

Comencé a leer la obra de María Rosa Lojo hace unos veinticinco años, en los que sus textos poéticos, ensayísticos y teatrales - un despliegue peculiar, signado por una imprecisión de géneros nunca azarosa- me han acompañado en mi propio camino de búsqueda, personal y académica. También he creído escuchar, al son de las gaitas, esa misma canción - por momentos perturbadora- que todas las mujeres de esta historia alguna vez hemos intuido, desde una Galicia verde y mágica que hace eco en esta Pampa húmeda.

Como se sabe, Argentina y, especialmente, esta ciudad porteña, ha sido uno de los grandes centros receptores de inmigrantes de distintas épocas y de exiliados republicanos, muchos de ellos artistas e intelectuales, aunque no solo. No voy a repetir aquello que ya fue largamente estudiado y debatido: los movimientos migratorios de España a la Argentina a lo largo ya de siglos... No es el propósito de este dossier continuar la indagación en ese sentido, sino repensar, a la luz de este nuevo siglo y en ocasión de este nuevo aniversario, la literatura de los hijos del exilio republicano español en Buenos Aires, en especial, de esta autora que considero ejemplo paradigmático de esta experiencia que, en su momento ${ }^{6}$, di en llamar exilio por herencia.

Hablar de la identidad como algo homogéneo, idéntico a sí mismo, resulta ya peregrino desde el punto de vista teórico, pero las problemáticas que proyecta no siempre siguen los derroteros de la razón ordenada. Lojo ha transitado escabrosos senderos, en los que ha intentado emprender un camino de regreso ( $i$ a su España soñada, a su Argentina natal?). Se ha afanado en aprehender, en el fondo, más que su identidad, su propia voz. Aunque, seguramente, no haya cabida para una sin la otra...

Resulta difícil recordar los momentos escriturarios significativos en la obra de Lojo para introducir este dossier, sin extenderme en exceso para un prólogo y sin repetirme a mí misma, por lo que prefiero -por una cuestión de honestidad intelectual- citar aquí un breve resumen (siempre inevitablemente injusto por esa brevedad) que escribí en ocasión de la publicación de Todos éramos hijos, su anteúltima novela, en la que:

Ambas guerras civiles ${ }^{7}$ se acercarán hasta casi fundirse, convivirán entre el tuteo hispánico y el voseo porteño; se colarán entre las zetas sonoras y las eses indistintas... cerrando un ciclo, tal vez, iniciado en aquella primera novela que publicara María Rosa Lojo en 1984, Canción perdida en Buenos Aires al Oeste, con otros - o los mismos - exiliados españoles: los Neira. El barco había llegado en ese entonces a puerto, se había convertido en una casa de Castelar, pero la pregunta apenas había sido susurrada... La hija — mitad española, mitad argentina - buscaba ese original perdido en el tránsito, guiada por una canción antigua que pronto se convertiría en marcha militar. Luego vendría el encantador dandy, Lucio V. Mansilla y su excursión a los indios ranqueles ${ }^{8}$, el exiliado de la historia, en un regreso fantasmal a fines de otro siglo, el $\mathrm{xx}$, en La pasión de los nómades, su segunda novela, publicada en 1995. En ella, haría dialogar la magia celta y el discurso histórico de la joven nación, dirigiendo la búsqueda hacia la Tierra Adentro9. También entre ranqueles, otra hija de Galicia, trasplantada a la Argentina, ensayaría la primera conciliación de la identidad escindida en Finisterre, novela aparecida en 2005. Su "Soy dos. Soy las dos" (Lojo, 2005: 181) parecía ser la clave, pero pocos años después, en 2012, Lojo publicó Árbol de familia e instaló el frío corredor para Rosa, la exiliada hija: un lugar de tránsito, en el que ningún descanso era posible. La búsqueda había llegado, tal vez, a una aporía. (Crespo Buiturón, 2014: 232)

El punto de partida parece ser siempre la omnipresencia de la nostalgia. El sentimiento de pérdida de algo que se va difuminando (la patria que se deja atrás) y va creando otro "original" inhallable, al que definitivamente nunca se podrá regresar, ya que esa patria habrá seguido su decurso histórico sin los exiliados, condenados a una muerte social que precederá dolorosamente a la física, y ya no será la misma que ellos idealizaran en el recuerdo. Por lo tanto, volver a aquel origen es, en sí misma, la mayor utopía del exiliado... que también heredarán los hijos.

Estos hijos habitan, entonces, la tierra accidental de acogida, la que hay que abandonar apenas se pueda, porque no es más que una copia deslucida:

\footnotetext{
${ }^{6}$ Me dediqué, en mi tesis doctoral (2008), a estudiar esos movimientos migratorios y, en especial, la literatura de los hijos del exilio en Buenos Aires (María Rosa Lojo, Miguel de Torre, Constanza Tobío, Álvaro Abós, etc.), en quienes entendí se operaba, en mayor o menor medida, este fenómeno de exilio por herencia.

${ }^{7}$ Me refiero aquí a la Guerra Civil Española (1936-1939) y a la última Dictadura Cívico-Militar en Argentina (1976-1983).

${ }^{8}$ Habitantes originarios de la Pampa.

${ }^{9}$ El interior del país, si se lo mira desde su Capital portuaria, Buenos Aires.
} 
Para el exiliado hijo el lugar de su nacimiento tiene a menudo la dudosa calidad de las copias platónicas, es un "mundo de segundo grado", en tono menor, a punto de desvanecerse, deslucido e insuficiente. De la historia y la geografía, hasta entonces, solo me habían hablado los libros de la escuela, incapaces de alcanzar el esplendor de la memoria viva y el peso candente del extrañamiento. (Lojo, 2006: 90)

Paradójicamente, muchos exiliados pretendieron ser, como comenta Lojo sobre su padre, "casi otra persona" (Lojo, 2006: 88) en la tierra de acogida, mientras obligaban a sus hijos a ser lo mismo que ellos habían sido en España... Otro-mismo, ajeno-propio... ¿Cómo sostener este pensamiento antinómico en general, pero aún más en la semántica del exilio?

Entre la ajenidad paterna de lo propio y la ajenidad filial en lo propio, lo único que podía filtrarse en los intersticios: una canción perdida que atraviesa prácticamente todos los textos de esta autora ${ }^{10}$. Es esa Canción perdida en Buenos Aires al Oeste que cuenta la historia de dos desgarros: la guerra, en sus múltiples ocurrencias (la de Malvinas, las luchas legendarias de la antigua Galicia y la Guerra Civil Española, que permiten focalizar los hechos desde la perspectiva del padre, quien enfatiza el sinsentido de tantas muertes); y la soledad (vivir en lugar ajeno, poblado de ausencias, que signará la mirada de la madre). Si está perdida, ¿qué letra le escribirá la hija del exilio? ¿Pretende hacerla resurgir del silencio, de aquello que no termina de pronunciarse y que acecha en cada línea de sus textos? De momento, el estribillo seguramente comenzaría glosando las palabras de Dolores, el personaje de La malasangre, de Griselda Gambaro: yo me callo, pero ¡el silencio grita!

Tal vez el primer grito, todavía silencioso, será contra el aislamiento social, la dualidad espacio-temporal y el conflicto identitario al que muchos padres, exiliados de todas las épocas y todas las procedencias, condenaron, seguramente sin quererlo, a sus hijos. Un grito de reclamo, que recordará la existencia de otros seres (¿exiliados también?) que luchan por ser y tener voz, y que terminan emergiendo desde el título de aquella novela de Lojo: Todos éramos hijos.

El camino recorrido es largo y sinuoso. Partir de Expaña (Colina, 1999), así con "x", aferrándose al espíritu de lo transitorio: “¿Por qué venían a Latinoamérica? No lo sabían con certeza. Este continente sería su refugio transitorio, una posada en el camino hasta que la noche se fuera de España" (Vázquez Rial 1998:26). E instalarse en otro país (nunca patria) llamado Exilio, ilocalizable en las fronteras dibujadas en los mapas, pero con la absoluta certeza de su existencia: es el primer acto de este drama infinito.

El segundo acto estaría dedicado, recordando el famoso epígrafe de Zama, de Antonio Di Benedetto, a las víctimas de la espera. Al demorarse cruelmente el momento del regreso, muchos exiliados desoyeron, porque significaría quedar varados en playas ajenas, el consejo de los viejos inmigrantes de otras épocas: “... si se piensa quedar a vivir: agárrese al vos, con fuerza, como hizo antes. Si habla de tú, va a ser siempre un extranjero" (Vázquez Rial, 1998: 46). Se aferrarían así a su lengua y sus costumbres:

Mi padre quería que se hablara el español de España, quería que se emplearan bien los verbos, que se emplearan ciertas palabras como acera; en fin, términos que son más españoles que argentinos [...]. Yo me acuerdo haber hablado dos idiomas, con los españoles con las zetas y con los argentinos, en argentino (Schwarzstein, 1999: 122).

Condenaron así a sus hijos no solo a la necesidad de, como se aprecia en la cita, hablar dos lenguas, sino también a habitar dos espacios en dos tiempos: una España que no claudica el pasado omnipresente, en la casa paterna, y una Argentina translúcida, con su presente impreciso.

El drama podría no tener final, porque el exilio (paterno y filial) no termina nunca... aunque en algunos casos pareciera que sí, pero hará falta un nuevo acto de rebeldía, otro grito: "Un hijo es algo más que un desdoblamiento del padre" (Lojo, 2014: 81).

Hace tiempo partí de esta pregunta para dar curso a mi tesis doctoral: “¿De qué manera afecta todo esto a los hijos de exiliados y a su literatura tanto en lo que atañe a los enunciados legitimados por el exilio paterno como a los otros enunciados silenciados?" (Crespo Buiturón, 2008: 47). Y pensé que esto configuraría el sociograma del exilio heredado.

${ }^{10}$ He realizado un seguimiento exhaustivo de la imagen de la canción en los textos de Lojo en mi tesis (82 y ss.). 


\section{4. ... en Buenos Aires al Sur}

¿Cuál es la perspectiva desde la que un hijo del exilio lee la historia que le ha tocado en suerte? Constancia Tobío Soler, en una entrevista que le hice en 2006, sostenía: "La pertenencia a dos países, que puede tener múltiples motivaciones, genera una cierta inseguridad en la interpretación de las cosas y en el cómo desenvolverse en cada situación; a la vez da una visión un poco más compleja de la realidad" (Crespo Buiturón, 2008: 247).

En el caso de Lojo, la perspectiva desde la que lee e interpreta la historia, la que han vivido sus familiares en España y la que ella experimenta en Argentina, ha sido -para bien o para mal, porque la ha ubicado en una posición conflictiva- el borde...Un espacio desde el que reflexiona tanto sobre el material narrativo como sobre los episodios de violencia colectiva que han atravesado sus padres y ella misma: la guerra civil española y la última dictadura cívico-militar argentina.

Pienso que el borde es el eje vertebrador de todas sus propuestas: tanto las ficcionales como las metaficcionales y ensayísticas. Desde el extremo oeste de Buenos Aires, Castelar -donde se halla la casa paterna que nunca ha abandonado-, hasta el extremo oeste de España, Galicia, narra la hija la historia de un exilio que nunca acaba... La mayoría de sus ficciones tienen como escenario esta ciudad porteña, pero así como para sus padres España es el único espejo que proyecta sus rostros (su identidad), la Tierra Adentro es, para la hija, uno de los grandes centros irradiadores de sentido: muchos de sus personajes emprenderán viajes (muchos de ellos planteados como iniciáticos) desde Buenos Aires hacia la Pampa, empezando por Lucio Mansilla en La pasión de los nómades, pasando por varios personajes de sus cuentos y novelas, hasta desembocar en la última, Solo queda saltar, de la que se discurrirá especialmente en este dossier.

Sin quererlo, tal vez, ambos, padres e hija, convierten a Buenos Aires en un espacio exterior, el espacio del exilio por excelencia. Sin embargo, es el lugar desde el que se narra, desde el que se intenta recordar esa canción perdida... Borde ambiguo y un intersticio fructífero: un espacio de creación.

Desde ese Buenos Aires al oeste, ¿cómo puede aprender la hija a no mirar "el tiempo con los ojos de infancia de mi padre" (Lojo, 1993: 60)? Es un camino de tránsito arduo, en el que no cesa de reflexionar, asistida por la memoria ancestral y por la indagación de la Historia narrada a contrapelo por sus marginales: Lucio Mansilla, Victoria Ocampo, Eduarda Mansilla, Eva Perón, los fantasmas ranqueles de la Pampa, los sacerdotes de la Teología de la Liberación... La historia argentina está presente en cada página explícitamente desde su primera novela, aunque ya sugerida en algunos de sus poemas iniciales: las guerras de la independencia, las luchas por la consolidación del Estado Nacional, la última dictadura cívico-militar, etc. -, pero difícil pensarla sin la sombra de la Guerra Civil Española: Sentía [...] que la generación de sus padres ya había probado y consumido hasta el fondo, sin dejarle a ella nada, la violencia y el riesgo de la Historia que arrasó las vidas y sobre todo las esperanzas, para que no volviera a crecer la hierba bajo los pies de los derrotados. (Lojo, 2014: 153)

Pensar desde la conciencia de la derrota de sus padres -siempre incrédulos, escépticos ante cualquiera que proponga una verdad que los conduzca a una nueva lucha-, los hijos sienten que: "Todos, todas, pasarían y morirían, pero ellos [...] habrían pasado sin vivir realmente, sin gastar, hasta el hueso, el tiempo que les correspondía, presos en el crepúsculo indeciso que prometía develarles una canción para otros inaudible" (Lojo, 2014: 102).

El silencio ensordecedor de quienes buscan recuperar esa canción-trampa, pero no lo consiguen, atrapados en ese entre-tiempo ("crepúsculo indeciso"), ese espacio sin certezas, a medio camino, sin poder entregarse a ninguno de los extremos de su sociedad siempre polarizada... La discusión, sea cual sea el color o el polo elegido (republicanos o franquistas; peronistas o militares...), parece sintetizarse en la conversación de los hijos:

-Cuando se hace una revolución social todos tienen que apoyarla.

$-¿$ Y tu libertad de decidir?

-¿Para qué sirve la libertad de decidir, Daniel, si va en contra del bien de la mayoría?

-A lo mejor no va en contra, es otra mirada.

-Si un movimiento político pudo cambiar de esa manera una sociedad, me parece que las otras miradas no sirven de mucho. Lo que cuenta son los hechos. Lo que cuenta es pertenecer, integrarse a la voluntad del pueblo. (Lojo, 2014: 64-65)

Queda claro que no hay lugar para otra mirada, para posiciones intermedias, para bordes... Pero lo que habría que preguntarse, entonces, es si realmente ese borde es una posición intermedia... si no es un gesto de profundo cuestionamiento a la polarización, a la mirada antinómica: un espacio que no logra definirse 
independiente, porque todavía arrastra la concepción binaria del mundo, pero que intenta proponer un enfoque otro que lucha por abrirse camino.

Podría decirse que Lojo intentó escapar de otras canciones conocidas: las que traía su familia con acordes de guerra civil, la marcha peronista o las marchas militares argentinas, y que cayó en un profundo silencio... pero yo creo que en lo que cayó, como ella misma percibe, es en la trampa de una canción perdida que nunca podría recuperarse, porque tiene letra ajena. Es la canción del exiliado. Sin embargo, la anhelada voz fue corporizándose en sus inclasificables versos narrados, en sus novelas liricas o dramáticas, en sus ensayos poéticos; visible, pero metamorfoseada en el gesto rebelde e incómodo de sus mujeres desaforadas, polémicas, mágicas... en sus fantasmas ranqueles... en la letra menuda, enlazada indisolublemente y para siempre al silencio que horada y teje sus historias.

Y esta voz ya soprano, en comunión de grito y silencio, es la que acompaña y da impulso al salto, del que hablarán los lectores de Lojo en este dossier.

Esta historia sin fin de un exilio desgarrador, a la vez que fuente inagotable de creación poética, es revisitada, en un lúcido recorrido intertextual, por Rosa María Grillo y Antonio Esteves, dando cuenta ambos de un exhaustivo conocimiento de la obra de esta autora; y es profundizada en la lectura sagaz de su última novela, Solo queda saltar, por Camila Bari, Maria Josele Bucco Coelho y Gracielle Marques.

Pero antes de estos trabajos, pensé que no solo la crítica debía volver a fatigar las páginas de la obra de esta autora, sino que también ella misma podía repensar su propia condición de exiliada hija tantos años después de su primera novela y en ocasión de la última, publicada poco antes del $80^{\circ}$ aniversario de aquel suceso que ha signado, en gran medida, su vida y obra.

Y aprovecho la ocasión de este escrito para agradecer la generosidad de Evangelina Soltero Sánchez, la editora de esta prestigiosa revista, por abrirnos este espacio de publicación para nuestro homenaje; a los experimentados colegas que contribuyeron con estos valiosos abordajes; y a la propia María Rosa Lojo por la magia de su pluma, que sigue convocándonos.

\section{Referencias bibliográficas}

Colina, José de la (1999), "La palabra exilio", Letras libres, año I, nº. 8, págs. 76-77.

Crespo Buiturón, Marcela (2008). Andar por los bordes. Entre la historia y la ficción: el exilio sin protagonistas de María Rosa Lojo. Biblioteca Virtual Miguel de Cervantes. Disponible en: http://www.cervantesvirtual.com/obra/andar-por-los-bordes-entre-la-historia-y-la-ficcion-el-exilio-sin-protagonistasde-maria-rosa-lojo--0/

(2014), "Recuperar la voz en el exilio: Apostillas a la última novela de María Rosa Lojo", Gramma. Revista de Letras, año XXV, nº. 53, págs. 231-234.

(2018), "Nota introductoria", en Marcela Crespo Buiturón (ed.). Diálogo de voces. Nuevas lecturas sobre la obra de María Rosa Lojo. North Carolina: Editorial A Contracorriente, págs. 1-3.

Lojo, María Rosa (1993), "España (Argentina) en el corazón. Los hijos de la posguerra", Revista del Hogar Gallego para Ancianos. Buenos Aires: Hogar Gallego para Ancianos, p. 60.

(2006), "Mínima autobiografía de una exiliada hija", en Manuel Fuentes Vázquez y Paco Tovar (eds.). L’exili literari republicà. Tarragona: URV, págs. 87-97 - (2014). Todos éramos hijos. Buenos Aires: Sudamericana.

Schwarzstein, Dora (1999), "Sociabilidades", en Fernando Devoto y Marta Madero (dirs.). Historia de la vida privada en Argentina. Tomo 3. Buenos Aires: Taurus, págs. 111-129.

Vázquez Rial, Horacio (1998). Frontera sur. Barcelona: Ediciones B. 